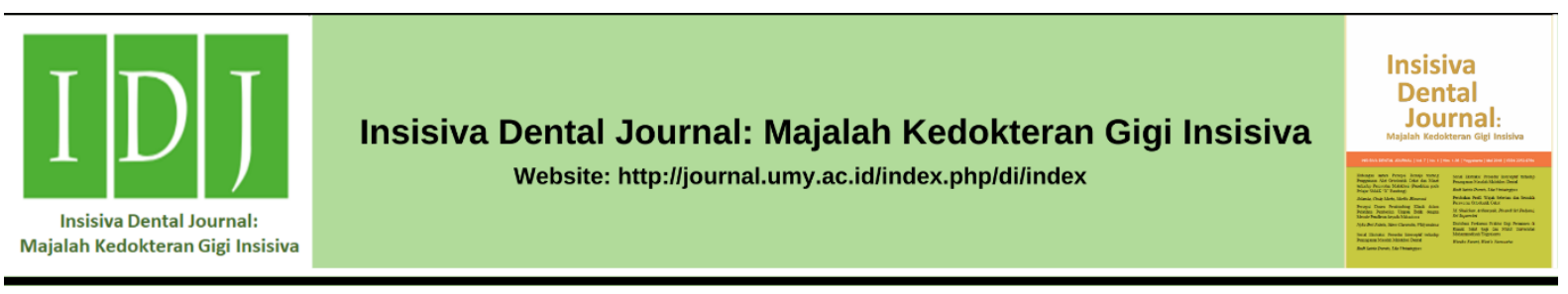

Research Article

\title{
Permainan Ular Tangga Meningkatkan Pengetahuan Kesehatan Gigi dan Mulut Anak Disabilitas Rungu
}

\author{
A Snake and Ladder's Game Improve the Deaf Children Oral Health
}

Nabilah Nur Dini ${ }^{1}$, Erna Dwi Agustin², Musri Amurwaningsih ${ }^{3, *}$

${ }^{1,2,3}$ Program Studi Kedokteran Gigi, Fakultas Kedokteran Gigi, Universitas Islam Sultan Agung, Jalan Kaligawe Raya No. KM 4, Terboyo Kulon, Kecamatan Genuk, Kota Semarang, Jawa Tengah, Indonesia

Received date: August $14^{\text {th }}, 2020$; reviewed date: April $3^{\text {rd }}, 2021$; revised date: April $9^{\text {th }}, 2021$; accepted date: April $21^{\text {st }}, 2021$ DOI : $10.18196 /$ di.v10i1.9566

\begin{abstract}
Abstrak
Anak disabilitas rungu memiliki keterbatasan pendengaran sehingga mengalami hambatan dalam perkembangan bahasa. Keterbatasan tersebut mempengaruhi tingkat pengetahuan anak terhadap informasi yang didapatkan. Tujuan penelitian ini untuk mengetahui pengaruh penyuluhan menggunakan permainan ular tangga dalam peningkatan pengetahuan kesehatan gigi dan mulut pada anak disabilitas rungu di SLB Negeri Semarang. Penelitian ini menggunakan rancangan Experimental dengan pre and post test group design. Sampel diambil dengan teknik total sampling yaitu seluruh siswa disabilitas rungu di SLB Negeri Semarang berjumlah 45 anak. Penelitian ini dilakukan sebanyak 5 kali pertemuan. Data dinalisis menggunakan uji Wilcoxon Signed Ranks Test. Berdasarkan hasil analisis data yang dilakukan, menunjukkan bahwa terdapat perbedaan yang signifikan $(\mathrm{p}<0,05)$ pada data sebelum dan sesudah dilakukan penyuluhan menggunakan permainan ular tangga yang artinya terdapat pengaruh pada penyuluhan menggunakan permainan ular tangga terhadap peningkatan pengetahuan kesehatan gigi dan mulut anak disabilitas rungu. Kesimpulan penelitian ini adalah penyuluhan menggunakan permainan ular tangga berpengaruh terhadap peningkatan pengetahuan kesehatan gigi dan mulut pada anak disabilitas rungu.
\end{abstract}

Kata Kunci: Disabilitas Rungu; Kesehatan Gigi dan Mulut; Permainan Ular Tangga; Tingkat Pengetahuan

\begin{abstract}
Deaf children have hearing disabilities and, thus, encounter difficulties in language development. Such limitations affect the child's level of knowledge of the information they receive. This study aims to identify the influence of education using a snake's and ladder's game in increased dental and oral hygiene on deaf children in the public school for disability, Semarang. This study is experimental with the pre and post-test group design. The sample was collected using a total sampling technique with a total of 45 students with deaf disabilities in Semarang. This study was conducted with a total of five separate meetings. Data analysis was carried out using Wilcoxon Signed Ranks Test. The data analysis indicated a significant difference $(p<0.05)$ in the data prior to the intervention of using the snakes' and ladder's game towards the deaf children's dental and oral health knowledge. It can be concluded that the use of the snake's and ladder's game led to increased dental and oral knowledge in children with deaf disability.
\end{abstract}

Keywords: Deaf; Dental and Oral Health; Level of Knowledge; Snake's and Ladder's Game

\footnotetext{
*Corresponding author, e-mail: musri@ unissula.ac.id
} 


\section{PENDAHULUAN}

Pemeliharaan kesehatan gigi dan mulut merupakan salah satu upaya untuk meningkatkan status kesehatan gigi dan mulut. ${ }^{1}$ Permasalahan dialami oleh manusia normal terlebih seseorang yang memiliki kebutuhan khusus. Kondisi yang diderita oleh anak berkebutuhan khusus membuat mereka sulit mendapatkan informasi, salah satunya mengenai kesehatan gigi dan mulut sehingga banyak penelitian yang menyatakan bahwa angka karies pada anak berkebutuhan khusus masih cukup tinggi. $\stackrel{2}{ }$

Belajar sambil bermain menjadi metode pembelajaran yang sering digunakan anak-anak termasuk anak disabilitas rungu karena dengan menggunakan metode ini mereka akan lebih mudah dalam menangkap materi yang disampaikan. Metode ini lebih menarik perhatian dan menyenangkan. ${ }^{3}$ Belajar sambil bermain memiliki banyak manfaat di antaranya membangun kreativitas diri, menghilangkan stress dalam lingkungan belajar dan meningkatkan proses belajar. ${ }^{4}$

Penelitian ini akan memberikan penyuluhan tentang kesehatan gigi dan mulut dengan menggunakan permainan ular tangga yang merupakan permainan yang sudah diketahui oleh semua orang. Permainan ular tangga berupa gambar dan tulisan yang dapat dilakukan untuk dua orang atau lebih. Permainan ular tangga dilakukan dengan cara mengocok dadu terlebih dahulu setelah itu baru menjalankan pionnya. Anak disabilitas rungu akan terlibat langsung dalam permainan ular tangganya sehingga mereka dapat lebih mudah untuk menerima informasi mengenai kesehatan gigi dan mulut. Pembelajaran dengan menggunakan media permainan ular tangga tidak hanya mengembangkan aspek kognitif saja, tetapi juga dapat mengembangkan keterampilan sosial. $\underline{5}$

Tujuan dari penelitian ini adalah mengetahui tingkat pengetahuan tentang kesehatan gigi dan mulut dengan penyuluhan menggunakan media permainan ular tangga pada anak disabilitas rungu. Manfaat dari penelitian ini adalah mencegah terjadinya penyakit gigi dan mulut pada anak disabilitas rungu serta membantu tenaga kesehatan untuk memberikan informasi tentang kesehatan gigi dan mulut. Hipotesis penelitian ini adalah penyuluhan menggunakan permainan ular tangga dapat berpengaruh dalam peningkatan pengetahuan anak disabilitas rungu dalam menjaga kesehatan gigi dan mulut.

\section{MATERIAL DAN METODE}

Jenis penelitian yang digunakan adalah penelitian experimental dengan pre and post test group design. Perhitungan besar sampel menggunakan total sampling sesuai dengan kriteria inklusi, didapatkan jumlah sampel 45 anak dengan setiap 1 kelas terdiri dari 2 kelompok. Subjek penelitian diberikan penyuluhan menggunakan permainan ular tangga selama 5 kali dengan durasi 45 menit/sesi.

Penelitian telah mendapatkan ijin ethical clearance (EC) dari komisi etik penelitian kesehatan fakultas kedokteran gigi Unissula dengan no. 143/B.1-KEPK/SAFKG/XI/2019 dan informed consent yang telah ditanda tangani oleh orangtua/wali serta mengerjakan pre-test lalu pemberian penyuluhan berupa media permainan ular tangga dan dilanjutkan dengan post-test.

Analisis data menggunakan SPSS versi 16.0 Tahun 2016. Uji normalitas data dilakukan dengan Shapiro Wilk (jumlah sampel $<50$ per kelompok). Apabila data dinyatakan normal, data dianalisis menggunakan uji Paired t-test. Apabila data tidak normal (asymp sig < 0.05) maka dilakukan analisis dengan uji Wilcoxon.

\section{HASIL}

Subjek penelitian ini dilakukan pada siswa disabilitas rungu di SLB Negeri Semarang dari kelas 1 hingga kelas 6 SD yang berjumlah 68 orang. Pada penelitian, terdapat 23 orang subjek yang tidak memenuhi kriteria inklusi karena tuna ganda sebanyak 12 orang dan tidak mengikuti pre atau post test sebanyak 11 orang sehingga jumlah total subek penelitian sebanyak 45 orang yang terdiri dari siswa laki-laki dan perempuan (Tabel 1). 
Tabel 1. Distribusi jumlah subjek berdasarkan jenis kelamin di SLB Negeri Semarang

\begin{tabular}{ccc}
\hline JENIS & JUMLAH & $\begin{array}{c}\text { PERSENTASE } \\
(\boldsymbol{\%})\end{array}$ \\
\hline KELAMIN & & $51 \%$ \\
Laki-Laki & 23 & $49 \%$ \\
Perempuan & 22 & $100 \%$ \\
Total & 45 & \\
\hline
\end{tabular}

Tabel 2. Hasil persentase nilai Pre-test dan Post-test penyuluhan permainan ular tangga tentang kesehatan gigi dan mulut

\begin{tabular}{ccccc}
\hline \multicolumn{2}{c}{ Pre-test } & \multicolumn{2}{c}{ Post-test } & $\begin{array}{c}\text { Selisih } \\
(\%)\end{array}$ \\
\hline $\begin{array}{c}\text { Jumlah } \\
\text { Benar }\end{array}$ & $\begin{array}{c}\text { Per- } \\
\text { sentase }\end{array}$ & $\begin{array}{c}\text { Jumlah } \\
\text { benar }\end{array}$ & $\begin{array}{c}\text { Per- } \\
\text { sentase }\end{array}$ \\
\hline $\mathbf{4 4}$ & $98 \%$ & 45 & $100 \%$ & $2 \%$ \\
$\mathbf{4 3}$ & $96 \%$ & 45 & $100 \%$ & $4 \%$ \\
$\mathbf{1 3}$ & $29 \%$ & 31 & $69 \%$ & $40 \%$ \\
$\mathbf{3 9}$ & $87 \%$ & 40 & $89 \%$ & $2 \%$ \\
$\mathbf{2 1}$ & $47 \%$ & 37 & $82 \%$ & $36 \%$ \\
$\mathbf{1 6}$ & $36 \%$ & 34 & $76 \%$ & $40 \%$ \\
$\mathbf{1 1}$ & $24 \%$ & 32 & $71 \%$ & $47 \%$ \\
$\mathbf{2 8}$ & $62 \%$ & 33 & $73 \%$ & $11 \%$ \\
$\mathbf{1 0}$ & $22 \%$ & 29 & $64 \%$ & $42 \%$ \\
$\mathbf{4 1}$ & $91 \%$ & 44 & $98 \%$ & $7 \%$ \\
\hline
\end{tabular}

Tabel 3. Ringkasan hasil uji statistik Wilcoxon Signed Ranks Test antara sebelum dan sesudah diberikannya penyuluhan permainan ular tangga tentang kesehatan gigi dan mulut

\begin{tabular}{lc}
\hline & Post test - Pre test \\
\hline \multicolumn{1}{c}{$Z$} & -5.891 \\
\hline $\begin{array}{l}\text { Asymp. } \\
\text { Sig. (2- } \\
\text { tailed) }\end{array}$ & $-.000^{*}$ \\
\hline
\end{tabular}

Keterangan: $(*)=p \leq 0,05$. Terdapat perbedaan signifikan antara tingkat pengetahuan sebelum dan sesudah penyuluhan

Tabel 1 menunjukkan bahwa subjek berjenis kelamin laki-laki lebih banyak daripada subjek berjenis kelamin perempuan pada anak disabilitas rungu tingkat Sekolah Dasar di SLB Negeri Semarang.

Tingkat pengetahuan kesehatan gigi dan mulut dalam penelitian ini diukur menggunakan pre dan post test yang terdiri dari 10 pertanyaan (soal). Tabel 2 diketahui terdapat 5 soal dari pre-test dan post-test yang memiliki selisih persentase $\geq 36 \%$. Uji normalitas dilakukan dengan metode Shapiro-Wilk karena jumlah sampel yaitu kurang dari 50. Berdasarkan hasil uji Normalitas, diperoleh data pre-test dan data post-test $\mathrm{p} \leq 0,05$ menunjukkan bahwa data tersebut tidak berdistribusi normal. Berdasarkan hasil yang diperoleh dari uji non parametrik Wilcoxon Signed Ranks Test di atas didapatkan nilai $\mathrm{p}=0,000(\mathrm{p} \leq$ $0,05)$ yang artinya terdapat pengaruh penyuluhan menggunakan permainan ular tangga terhadap tingkat pengetahuan kesehatan gigi dan mulut (Tabel 3).

\section{PEMBAHASAN}

Sampel dalam penelitian ini dengan jumlah jenis kelamin laki-laki lebih banyak daripada jenis kelamin perempuan. Menurut Riskesdas bahwa jumlah penyandang disabilitas pada usia 5-17 tahun berdasarkan jenis kelamin sebanyak $3,4 \%$ untuk laki-laki dan $3,1 \%$ untuk perempuan. $\underline{6}$

Penyebab terbesar pada disabilitas rungu disebabkan oleh abnormalitas genetik, bisa dominan atau resesif. ${ }^{7}$ Faktor genetik terjadi karena adanya abnormalitas pada kromosom $\mathrm{X}$ sehingga disabilitas rungu bisa terjadi pada laki-laki maupun perempuan. Kromosom pada laki-laki yaitu kromosom XY jika kromosom X ini terjadi kelainan maka gen laki-laki sebagai faktor pembawa dominan kelainan tersebut sedangkan pada perempuan memiliki kromosom XX jika salah satu kromosom terjadi kelainan maka hasilnya perempuan tetap normal atau bisa jadi resesif faktor pembawa kelainan tersebut. Oleh karena itu laki-laki memiliki banyak kemungkinan untuk mengalami disabilitas. $\underline{-}$

Tabel 2 dijelaskan bahwa terdapat 2 pertanyaan yang mengalami peningkatan hingga $>40 \%$. Pada pertanyaan nomor 7 tentang "arah menyikat gigi" mengalami peningkatan $47 \%$ karena pada saat penyuluhan menggunakan permainan ular tangga (gambar 1) di kotak nomor 5, nomor 
14, dan nomor 17 , peneliti meminta kepada anak-anak disabilitas rungu untuk memperagakan cara menyikat gigi dengan teknik roll mengggunakan phantom dan sikat gigi dengan menirukan gerakan yang ada pada poster cara menyikat gigi (gambar 2). Selain itu, peneliti juga membantu menjelaskan step by step kepada anak dengan menggunakan bahasa yang lebih mudah dipahami oleh anak karena pembelajaran dengan cara meniru dan memperagakan merupakan proses melakukan dan mengalami sendiri apa yang dipelajari sehingga anak lebih mendalam dalam memahami materi yang diberikan. ${ }^{?}$

Pertanyaan nomor 9 tentang "akibat malas menyikat gigi" mengalami peningkatan sebesar $42 \%$. Namun, materi ini di media permainan ular tangga tidak terdapat gambar bau mulut sehingga peneliti menjelaskan dengan menggunakan gerakan bibir dan bahasa tubuh. Anak disabilitas rungu bisa mengerti dengan cara membaca gerakan bibir dan bahasa tubuh karena cara ini merupakan salah satu bentuk untuk berinteraksi dengan anak disabilitas rungu. $\underline{10}$

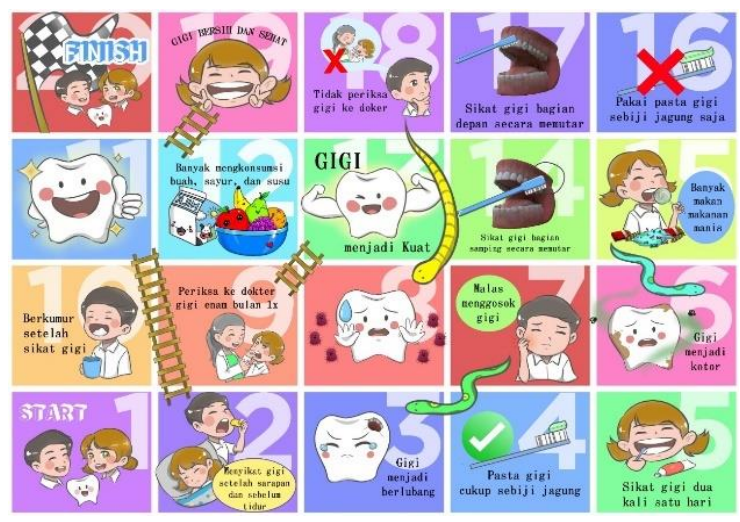

Gambar 1. Permainan Ular Tangga

Penyuluhan ini dilakukan dengan menggunakan media permainan ular tangga sebanyak 5 kali pertemuan secara berturutturut. Pengulangan bertujuan sebagai reinforced agar informasi yang disampaikan dapat tersimpan dalam memori jangka panjang. $\frac{11}{}$ penyuluhan ini dilakukan setiap 1 harinya diberikan waktu selama \pm 45 menit yang dilakukan secara berulang-ulang. Permainan ini dilakukan hingga mencapai finish dan bisa diulang kembali karena anak disabilitas rungu memiliki daya ingat yang lebih rendah daripada anak yang bisa mendengar normal. $\stackrel{12}{~ p e n g u l a n g a n ~ d a l a m ~ k e g i a t a n ~}$ belajar mengajar anak disabilitas rungu dapat mempengaruhi kesuksesan dalam pembelajaran karena pengulangan yang dilakukan secara terus menerus dapat mengubah memori jangka pendek menjadi memori jangka panjang serta pemahaman menjadi semakin mendalam terhadap materi yang diberikan. $\frac{11}{}$

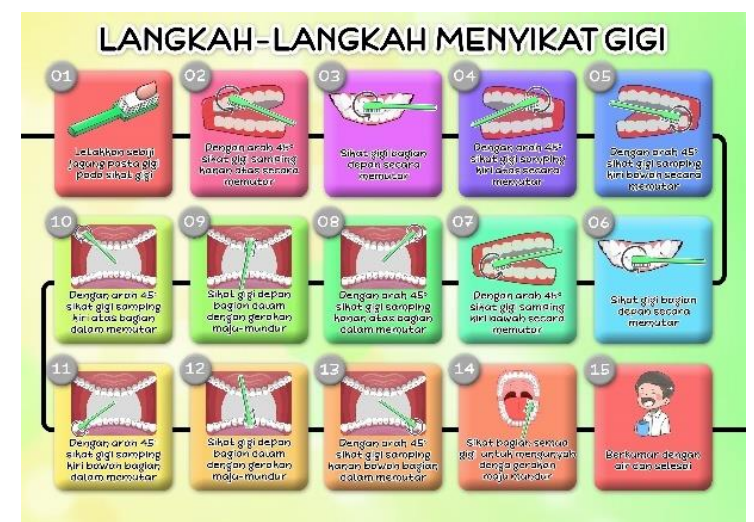

Gambar 2. Poster menyikat gigi

Anak disabilitas rungu di kelas 1 dan 2 SD, membutuhkan penjelasan yang lebih spesifik dalam penyampaian informasi. Namun peneliti tidak menyediakan media lainnya seperti gambar buah-buahan, sayursayuran, coklat dan permen. Hal ini menyebabkan peneliti kesulitan dalam memberikan penjelasan yang lebih konkrit. Setiap selesai bermain, anak disabilitas rungu diberikan review materi dengan dibantu oleh guru agar memudahkan dalam komunikasi.

Hal ini dikarenakan anak kelas 1 sampai kelas 3 mereka berada di usia sekitar 7-11 tahun. Usia ini berada pada tahap operasional konkrit dimana masa anak mulai memiliki kemampuan untuk mengetahui simbol-simbol matematis, namun belum dapat menghadapi hal-hal yang abstrak. Sehingga ketika menjelaskan materi anak-anak harus dijelaskan secara spesifik. $\underline{5}$ 
Anak kelas 4 sampai kelas 6 tidak ada kendala dalam memberikan penyuluhan sehingga ketika memberikan review tidak memerlukan bantuan dari guru. Hal ini dikarenakan mereka berada di usia sekitar 11 tahun ke atas yang dimana mereka berada pada tahap operasi formal sehingga anak telah memiliki kemampuan berfikir abstrak dan berbuat berdasarkan hipotesisnya yang dinilai relevan dengan lingkungannya sehingga ketika menjelaskan materi lebih mudah dari pada anak kelas 1 sampai 3. ${ }^{13}$

Anak kelas 4 sampai kelas 6 tidak ada kendala dalam memberikan penyuluhan sehingga ketika memberikan review tidak memerlukan bantuan dari guru karena mereka berada di usia sekitar 11 tahun ke atas yang dimana mereka berada pada tahap operasi formal sehingga anak telah memiliki kemampuan berfikir abstrak dan berbuat berdasarkan hipotesisnya yang dinilai relevan dengan lingkungannya sehingga ketika menjelaskan materi lebih mudah dari pada anak kelas 1 sampai 3. $\underline{13}$

Perubahan pengetahuan pada anak disabilitas rungu dapat terjadi karena penggunaan media yang mempermudah dalam memperoleh informasi. Sebagian besar pengetahuan manusia didapatkan melalui indra penglihatan serta pendengaran yakni mata dan telinga. $\underline{14}$ Keterbatasan yang dimiliki anak disabilitas rungu yaitu keterbatasan kemampuan indra pendengarannya dapat disiasati dengan penyampaian informasi yang mudah diterima oleh indra penglihatan dengan menggunakan media permainan yang konkret diilustrasikan dalam bentuk gambar. 15

Permainan ular tangga dalam penyuluhan kesehatan gigi dan mulut dapat dikatakan sesuai untuk anak disabilitas rungu karena media menggunakan konsep bermain sambil belajar, sehingga anak-anak merasa tidak jenuh dalam memperhatikan materi penyuluhan, selain itu permainan ini juga dapat dilakukan secara berkelompok sehingga dapat meningkatkan kerja sama dan sportifitas antar anggota kelompok. $\underline{16}$
Penggunaan permainan ular tangga ini sesuai dengan prinsip pembelajaran anak disabilitas rungu yaitu belajar sambil melakukan. Anak disabilitas rungu dapat mempraktikkan secara langsung sehingga materi yang didapatkan lebih bermakna dan mudah diaplikasikan dalam kehidupan sehari-hari. $\frac{17}{}$

Penelitian ini memiliki beberapa keterbatasan di antaranya adalah pemahaman apa yang diucapkan dan diinginkan subjek serta keterbatasan mengendalikan kegaduhan saat penelitian dilakukan. Penelitian ini terdapat satu kelompok subjek dan tidak ada kelompok kontrol atau pembanding.

\section{KESIMPULAN}

Berdasarkan hasil penelitian yang telah dilakukan dapat disimpulkan bahwa terdapat pengaruh tingkat pengetahuan kesehatan gigi dan mulut pada anak disabilitas rungu setelah diberikan penyuluhan menggunakan media permainan ular tangga.

\section{DAFTAR PUSTAKA}

1. Husna N, Prasko P. Efektivitas Penyuluhan Kesehatan Gigi Dengan Menggunakan Media Busy Book Terhadap Tingkat Pengetahuan Kesehatan Gigi Dan Mulut. J Kesehatan Gigi. 2019;6(1):51-55.

2. Binkley CJ, Johnson KW, Abadi M, Thompson K, Shamblen SR, Young L, et al. Improving the oral health of residents with intellectual and developmental disabilities: an oral health strategy and pilot study. Eval Program Plann. 2014;47:54-63.

3. Setiawan I, Mujtaba M, Zuana M, Chalim A. Teaching Vocabulary Using Modified Snakes and Ladders Game. ALSUNA J Arab English Lang. 2018;1(87):87-95.

4. Yusuf Y, Auliya U. Sirkuit Pintar: Melejitkan Kemampuan Menghafal Matematika dan Bahasa Inggris 
dengan Metode Ular Tangga. cetakan pe. SR Z, Fauzi I, editors. Jakarta: Visimedia; 2011. 16-17.

5. Chabib M, Djatmika ET, Kuswandi D. Efektivitas Pengembangan Media. J Pendidik Teor Penelitian, dan Pengetah. 2017;2:910-8.

6. RI KK. Kementrian Kesehatan Republik Indonesia. 2018. 99-103.

7. Desiningrum RD. Psikologi anak berkebutuhan khusus. Cetakan Pertama. Vol. 3. Yogyakarta: Psikosain; 2016. 777-786.

8. Korver AMH, Smith RJH, Camp G Van, Schleiss MR, Lustig LR, Usami $\mathrm{S}$, et al. Congenital hearing loss. Primer. 2017;3:1-17.

9. Rifai. Penerapan Metode Demonstrasi untuk Meningkatkan Hasil Belajar Pendidikan Agama Kristen Materi Pembelajaran Sakramen Perjamuan Kudus VIII SMP Negeri 17 Surakarta,. Dun (J Teol dan Pendidik Kristiani ). 2017;1(2):172-92.

10. Rohman BN. Pelaksanaan Pembelajaran Bina Wicara Bagi Siswa Tunarungu di SLB Negeri 2 Bantul. J Widia Ortodidaktika. 2018;7(6):66275.

11. Kusumaningtyas ED, Purbaningrum E. Pendekatan Saintifik dalam Pembelajaran Menulis Anak Tunarungu Kelas V di SDLB-B. J Pendidik Khusus. 2017;9(3):1-9.
12. Tantra FHA. Penggunaan Media POPUP Untuk Meningkatkan Kosakata Anak Tunarungu Kelas P1 Di SLB Dena Upakara Wonosobo. J Widia Ortodidaktika. 2016;5(1):1194-204.

13. Syarifin A. Percepatan Perkembangan Kognitif Anak: Analisis Terhadap Kemungkinan dan Persoalannya. alBahtsu. 2017;2(1).

14. Notoatmojo S. Metodologi Penelitian Kesehatan. Jakarta: Rineka Cipta; 2014.

15. Effendi D, Hardiyana B, Gustiana I. Implementasi Rancangan Aplikasi Program Pembelajaran IPA Materi Sistem Pernafasan Untuk SDLB Bagian B Tunarungu Berbasis Multimedia. J Simetris. 2017;8(1):99112.

16. Juliani, Asriati N, Syahrudin $\mathrm{H}$. Efektivitas Pembelajaran Make A Match dalam Pemahaman Konsep Mata Pelajaran Ekonomi. 2017;1-11.

17. Hasan Y. Pelaksanaan Bina Bicara Melalui Pembelajran Individual Bagi Anak Tunarungu Di SLB Karya Tabing Padang. Pedagogi. 2017;XVII(1):29-35. 